Case report

\title{
Relapse of diabetic ketoacidosis secondary to insulin pump malfunction diagnosed by capillary blood 3-hydroxybutyrate: a case report John Scott Baird
}

Address: Department of Pediatrics, Columbia University, New York, NY 10032-3784, USA

Email: jsb106@columbia.edu

Received: 27 May 2009 Accepted: 14 July 2009 Published: 5 August 2009

Cases Journal 2009, 2:8012 doi: 10.4076/I757-1626-2-80I2

This article is available from: http://casesjournal.com/casesjournal/article/view/80I2

(C) 2009 Baird.; licensee Cases Network Ltd.

This is an Open Access article distributed under the terms of the Creative Commons Attribution License (http://creativecommons.org/licenses/by/3.0),

which permits unrestricted use, distribution, and reproduction in any medium, provided the original work is properly cited.

\begin{abstract}
A 14 year old female with type I diabetes mellitus and a subcutaneous insulin pump was treated for diabetic ketoacidosis presumed secondary to dietary indiscretion, and then restarted her subcutaneous insulin pump after exchanging the tubing. An hour later, nursing review determined that she was using outdated insulin in the pump, and it was exchanged. However, 5 hours later relapse was suggested by a rise in capillary blood 3-hydroxybutyrate, in spite of a normal serum anion gap and a minimal increase in serum bicarbonate. Insulin pump failure was suspected, and the patient was treated for relapse of diabetic ketoacidosis. Following resolution, her insulin pump was replaced without further complications. Capillary blood levels of 3-hydroxybutyrate may be sensitive, early indicators of relapse of diabetic ketoacidosis, and are easily obtained.
\end{abstract}

\section{Introduction}

A capillary blood assay for 3-hydroxybutyrate (BHB) has been used at home [1], in hospital emergency departments $[2,3]$ and during hospitalization [4-7] to diagnose and help manage patients with diabetic ketoacidosis (DKA). Capillary blood BHB tests have been used to document the persistence of ketones even while the urine nitroprusside test for ketones showed their clearance during therapy for DKA [8], and one might predict that these capillary blood BHB tests would have utility in detecting relapse following therapy for DKA. Nevertheless, capillary blood BHB testing is not yet routinely available in all children's hospitals.

An adolescent with a subcutaneous insulin pump and DKA is reported with an early relapse due to insulin pump malfunction, diagnosed by an increase in capillary blood
BHB prior to any increase in the anion gap or decline in serum bicarbonate. This case provides further support for the need to monitor capillary blood BHB during therapy for pediatric DKA.

\section{Case presentation}

A 14 year old Caucasian female (United States citizen) with type 1 diabetes mellitus and therapy with a subcutaneous insulin pump for a year, was admitted with severe [9] DKA (arterial blood gas pH 6.96), with serum glucose: $816 \mathrm{mg} /$ $\mathrm{dL}, \mathrm{PaCO}_{2}: 17 \mathrm{mmHg}$, serum anion gap: 38 , and $3+$ ketones on serum nitroprusside test. She noted dietary indiscretion. Additional laboratory data on admission included serum sodium $120 \mathrm{mmol} / \mathrm{L}$, potassium $5.1 \mathrm{mmol} / \mathrm{L}$, chloride $78 \mathrm{mmol} / \mathrm{L}$, bicarbonate $<5 \mathrm{mmol} / \mathrm{L}$, blood urea nitrogen $40 \mathrm{mg} / \mathrm{dL}$, creatinine $1.2 \mathrm{mg} / \mathrm{dL}$, and calcium $10.2 \mathrm{mg} / \mathrm{dL}$. 
After written informed consent and with IRB approval (University Hospital, University of Medicine and Dentistry of New Jersey in Newark, New Jersey), hourly testing of capillary blood BHB (using the Precision Xtra System for BHB; Abbott Laboratories, MediSense Products Inc; Bedford, MA) was performed concurrently with glucose (fingerstick) testing (Figure 1). Her insulin pump was discontinued, and she received a continuous infusion of intravenous insulin ( 0.1 to 0.14 units $/ \mathrm{kg} / \mathrm{hr}$ ) and rehydration. The serum anion gap and capillary blood BHB fell to normal levels ( $<12$ and $<0.5 \mathrm{mmol} / \mathrm{L}$, respectively) at 14 hours. Due to persistent metabolic acidosis, the insulin infusion was continued for a total of 42 hours, when serum [bicarbonate] was $18 \mathrm{mmol} / \mathrm{L}$. She felt much better and resumed her regular diet and therapy with her subcutaneous insulin pump (after changing all pump tubing).

Serum bicarbonate fell to $15 \mathrm{mmol} / \mathrm{L}$ while serum chloride increased to $116 \mathrm{mmol} / \mathrm{L}$ (serum anion gap: 9) less than 1 hour later. Subsequently, she had a meal as well as a snack. Within an hour of restarting the insulin pump, nursing staff determined that the patient had been using outdated insulin, and this was rectified. She was given several extra doses of subcutaneous (regular) insulin over the next 4 hours. Five hours after discontinuation of the intravenous insulin infusion, serum bicarbonate rose slightly to $16 \mathrm{mmol} / \mathrm{L}$ and the anion gap was 9, though hyperglycemia recurred (serum glucose: $501 \mathrm{mg} / \mathrm{dL}$ ).

Simultaneously, capillary blood BHB rose to $1.1 \mathrm{mmol} / \mathrm{L}$. The insulin pump was again stopped and the patient received 20 more hours of intravenous insulin infusion and hydration; her serum bicarbonate was then $24 \mathrm{mmol} /$ $\mathrm{L}$ with euglycemia. The pump was then replaced due to a malfunction, and the patient was discharged home without further complications.

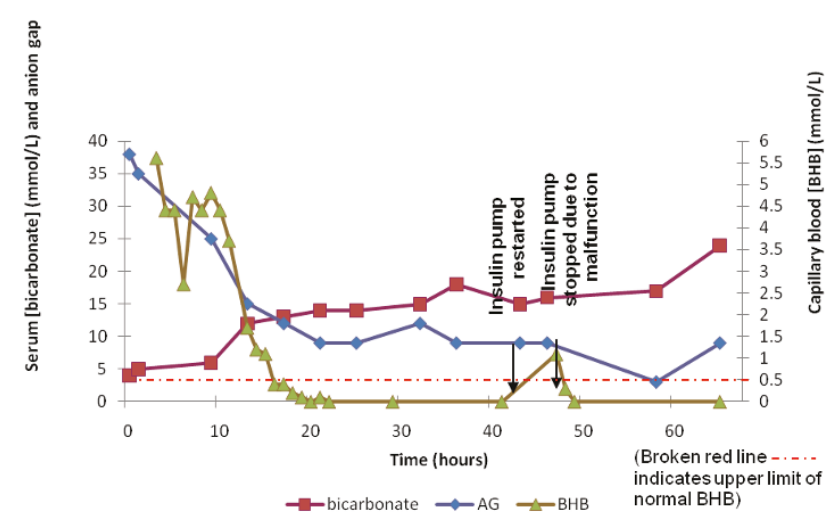

Figure I. Serum [bicarbonate] and anion gap (AG) with capillary blood $[\mathrm{BHB}]$ in patient with DKA and subcutaneous insulin pump.

\section{Discussion}

An episode of DKA in a patient with a subcutaneous insulin pump mandates a detailed review to discover the cause: in this patient, a dietary indiscretion was initially suspected, though outdated insulin was subsequently noted and exchanged. However, mechanical pump failure complicated this case, and was responsible for relapse shortly following resumption of a normal diet.

At the time relapse was diagnosed, the serum bicarbonate had increased slightly with concurrent hyperchloremic metabolic acidosis and postprandial hyperglycemia. Hyperchloremic metabolic acidosis may be associated with DKA, either on presentation or as a result of therapy [10], as in this patient. Nevertheless, the capillary blood BHB was also tested and confirmed relapse of DKA [11] secondary to subcutaneous insulin pump malfunction. Progressive ketosis can develop soon after interruption of a continuous insulin infusion in diabetics [12]. It is likely that recognition of DKA relapse in this patient would have been delayed in the absence of capillary blood $\mathrm{BHB}$ testing.

Interest and experience with subcutaneous insulin pump therapy is increasing [13], and practical experience with the management of these patients while hospitalized may be helpful. Multiple triggers for DKA may be present in diabetic children treated with a subcutaneous insulin pump, as in this patient. Capillary blood BHB is helpful in detecting relapse: a fingerstick BHB level is easily obtained at the bedside in conjunction with a glucose level and does not entail significant delays in processing. Capillary blood BHB levels have been recommended as routine for managing sick children with diabetes [1], and this technology "is a useful adjunct to laboratory-based determinations" according to a consensus statement from the American Diabetes Association [9]. It may be particularly useful for monitoring sick children with diabetes and a subcutaneous insulin pump [14].

\section{Abbreviations}

BHB, 3-hydroxybutyrate; DKA, diabetic ketoacidosis; IRB, institutional review board.

\section{Consent}

Written informed consent was obtained from the patient's parent and assent from the patient for publication of this case report and accompanying images. A copy of the written consent is available for review from the journal's Editor-in-Chief.

\section{Competing interests}

The author has no financial or other conflict of interest regarding the publication of this case report. 


\section{References}

I. Laffel LM, Wentzell K, Loughlin C, Tovar A, Moltz K, Brink S: Sick day management using blood 3-hydroxybutyrate (3-OHB) compared with urine ketone monitoring reduces hospital visits in young people with TIDM: a randomized clinical trial. Diabet Med 2006, 23:278-284.

2. Naunheim R, Jang TJ, Banet G, Richmond A, McGill J: Point-of-care test identifies diabetic ketoacidosis at triage. Acad Emerg Med 2006, 13:683-685.

3. Bektas F, Eray O, Sari R, Akbas H: Point of care blood ketone testing of diabetic patients in the emergency department. Endocr Res 2004, 30:395-402.

4. Vanelli M, Chiari G, Capuano C: Cost effectiveness of the direct measurement of 3-beta-hydroxybutyrate in the management of diabetic ketoacidosis in children. Diabetes Care 2003, 26:959.

5. Umpierrez GE, Watts NB, Phillips LS: Clinical utility of betahydroxybutyrate determined by reflectance meter in the management of diabetic ketoacidosis. Diabetes Care 1995, I 8: $137-138$

6. Wiggam MI, O'Kane MJ, Harper R, Atkinson AB, Hadden DR, Trimble ER, Bell PM: Treatment of diabetic ketoacidosis using normalization of blood 3-hydroxybutyrate concentration as the endpoint of emergency management. A randomized controlled study. Diabetes Care 1997, 20:1347-1352.

7. Noyes KJ, Crofton P, Bath LE, Holmes A, Stark L, Oxley CD, Kelnar CJ: Hydroxybutyrate near-patient testing to evaluate a new end-point for intravenous insulin therapy in the treatment of diabetic ketoacidosis in children. Pediatr Diabetes 2007, 8:150-I56.

8. Nadgir UM, Silver FL, MacGillivray MH: Unrecognized persistence of beta-hydroxybutyrate in diabetic ketoacidosis. Endocr Res 200I, 27:4l-46.

9. Wolfsdorf J, Glaser N, Sperling MA: Diabetic ketoacidosis in infants, children, and adolescents: a consensus statement from the American Diabetes Association. Diabetes Care 2006, 29:1150-1159.

10. Adrogue HJ, Wilson H, Boyd AE 3rd, Suki WN, Eknoyan G: Plasma acid-base patterns in diabetic ketoacidosis. N Engl J Med I982, 307:1603-1610.

I I. Laffel L: Ketone bodies: a review of physiology, pathophysiology and application of monitoring to diabetes. Diabetes Metab Res Rev 1999, 15:412-426.

12. Pickup JC, Viberti GC, Bilous RW, Keen H, Alberti KG, Home PD, Binder C: Safety of continuous subcutaneous insulin infusion: metabolic deterioration and glycaemic autoregulation after deliberate cessation of infusion. Diabetologia 1982, 22: I75-I79.

13. Tamborlane WV, Swan K, Sikes KA, Steffen AT, Weinzimer SA: The renaissance of insulin pump treatment in childhood type I diabetes. Rev Endocr Metab Disord 2006, 7:205-2I3.

14. Samuelsson U, Ludvigsson J: When should determination of ketonemia be recommended? Diabetes Technol Ther 2002, 4:645650 .

\section{Do you have a case to share?}

\section{Submit your case report today}

- Rapid peer review

- Fast publication

- PubMed indexing

- Inclusion in Cases Database

\section{Any patient, any case, can teach us something}

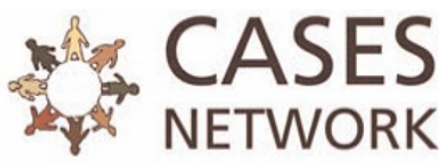

www.casesnetwork.com 